\title{
THYROID-USG DOPPLER IN DIFFERENTIATING FOLLICULAR ADENOMA OF THYROID FROM FOLLICULAR CARCINOMA
}

\author{
W. Edwina Vasantha ${ }^{1}$, A. Muthuvinayagam², V. Marimuthu³, S. Jeeva ${ }^{4}$
}

1Professor, Department of General Surgery, Thanjavur Medical College, Thanjavur.

${ }^{2}$ Assistant Professor, Department of General Surgery, Thanjavur Medical College, Thanjavur.

${ }^{3}$ Senior Assistant Professor, Department of General Surgery, Thanjavur Medical College, Thanjavur.

${ }^{4}$ Postgraduate Student, Department of General Surgery, Thanjavur Medical College, Thanjavur.

\begin{abstract}
BACKGROUND

In population older than fifty years of age, about 50\% develop thyroid nodules. Among them, $5 \%$ of these nodules are malignant, but it does not eliminate the need to screen benign nodules and differentiate it from malignant nodules. Usual B-mode USG cannot differentiate benign nodules from malignant nodules. FNAC is not always diagnostic. It cannot differentiate follicular adenoma from follicular carcinoma. These limitations can be bridged by using high frequency Doppler scan that can detect blood flow in thyroid gland and other superficial tissues. Doppler USG provides information about nodule vascularisation and is useful in identification of at risk nodules for malignancy by analysing various parameters like resistance index, pulsatility index and filling patterns.
\end{abstract}

\section{MATERIALS AND METHODS}

This is a prospective study in patients with thyroid nodules. One hundred seventy-seven patients with solitary thyroid nodule were analysed. Patients were recruited after obtaining informed consent, details of clinical diagnosis, preoperative investigations, FNAC, USG neck and USG Doppler, postoperative histopathology, followup period were recorded. Data analysed and results interpreted. Ethical approval for the study was obtained from ethical committee, Thanjavur Medical College and Hospital, Thanjavur.

\section{RESULTS}

One hundred seventy-seven patients with solitary thyroid nodule were analysed, sex distribution found to be 171 women and 6 men at our hospital. Based on echogenicity using B-mode USG, sixty nine of the hundred and seventy-seven nodules were hypoechoic, ten were hyperechoic, twenty were isoechoic, seventy-two were mixed and six were anechoic. Twenty nine of thirty-seven malignant nodules were hypoechoic. Eighty seven of the hundred and seventy-seven nodules showed peripheral halo. Depth, width and length measurements showed that malignant nodules were larger than indeterminate and benign nodules $(\mathrm{P}=0.001)$. Malignant nodules had an average width of $3.5 \mathrm{~cm}$ vs. $1.75 \mathrm{~cm}$ for benign nodules. Malignant nodules had an average width of $3.5 \mathrm{~cm}$ vs. $1.75 \mathrm{~cm}$ for benign nodules. 50 of the 177 nodules showed calcifications. Among 50 nodules with calcifications, 10 were coarse, fine in 37 , mixed in 3. Twenty Seven of the 37 nodules with microcalcifications had malignant cytology. Vascularisation patterns were identified with Power Doppler USG on all 177 nodules. It revealed that thirteen nodules with pattern I (absent blood flow), sixty-one had pattern II (exclusively perinodular blood flow), sixty-six had pattern III (perinodular blood flow equal or greater than central flow), twenty-six had pattern IV (central blood flow greater than perinodular flow), eleven had pattern V (exclusively central blood flow). Using pulsed Doppler in malignant nodules, mean PI is 1.54, (SD 0.033) and mean RI is 0.75 (SD 0.29).

\section{CONCLUSION}

Power Doppler and RI have a high sensitivity and specificity in detecting malignancy. Thus, based on the fact that tumours have increased blood flow, using the USG Doppler, we were able to differentiate follicular adenomas and follicular carcinoma. This is a noninvasive procedure and can bridge the limitation of FNAC, which cannot identify malignant follicular neoplasm.

\section{KEYWORDS}

Follicular adenoma, B-Mode USG, Pulsatility Index, Follicular Carcinoma, Pulsed Doppler.

HOW TO CITE THIS ARTICLE: Vasantha WE, Muthuvinayagam A, Marimuthu V, et al. Thyroid-USG Doppler in differentiating follicular adenoma of thyroid from follicular carcinoma. J. Evolution Med. Dent. Sci. 2017;6(20):1603-1606, DOI: $10.14260 /$ Jemds/2017/352

\section{BACKGROUND}

In community, population older than fifty years of age, about $50 \%$ develop thyroid nodules. Among them, 5\% of these nodules are malignant, but it does not eliminate the need to

Financial or Other, Competing Interest: None.

Submission 28-01-2017, Peer Review 25-02-2017,

Acceptance 02-03-2017, Published 09-03-2017.

Corresponding Author:

Dr. W. Edwina Vasantha,

Room No. 28, Lords Hostel,

Thanjavur Medical College, Thanjavur.

E-mail: suguplay@gmail.com

DOI: $10.14260 /$ jemds $/ 2017 / 352$

\section{(c) $(1) \$$}

screen benign nodules and differentiate it from malignant nodules. Thyroid scan-B-mode shows characters like dimension, contour, echogenicity, presence and type of peripheral halo. It also demonstrates the number of nodules.

But, usual B-mode USG cannot differentiate benign nodules from malignant nodules. In evaluation of thyroid swelling, FNAC plays a vital role. But, FNAC is not always diagnostic. Moreover, FNAC cannot differentiate follicular adenoma from follicular carcinoma. These limitations can be bridged by using high frequency Doppler scan, that can detect blood flow in thyroid gland and other superficial tissues. It is based on the simple principle that increase in vascularity is associated with increased proliferation of cells. Doppler USG provides 
information about nodule vascularisation and is useful in identification of at risk nodules for malignancy by analysing various parameters like resistance index, pulsatility index and filling patterns.

The aim of our study was to evaluate that Doppler USG is useful in diagnosing thyroid nodules at risk for malignancy, more importantly in differentiating benign follicular neoplasm from malignant follicular neoplasm. It aids in management of patients with solitary nodule of thyroid with high risk for malignancy that they may directly undergo total thyroidectomy rather than going for hemithyroidectomy and later for second stage completion thyroidectomy.

\section{MATERIALS AND METHODS}

One hundred seventy-seven patients with solitary thyroid nodule were analysed, sex distribution found to be 171 women \& 6 men at our hospital. Age distribution found to be 15 to 75 years (Mean 42 years). Once the presence of thyroid nodules was confirmed clinically, FNAC was done. These people were subjected to ultrasound of neck along with Doppler imaging, we included only the nodules for which representative cytological material was available in FNAC. Ethical committee clearance was obtained, and patients were enrolled for study after getting informed consent.

All Doppler scans were performed with Siemens Acuson, high-frequency variable linear transducer, frequency used is $10 \mathrm{MHz}$ (7.5 MHz to $10 \mathrm{MHz}$ ).

Microscopic study of the FNAC specimens demonstrated that 119 of the 177 nodules were benign, 29 had indeterminate cytology (follicular cells/neoplasm) and 29 were malignant.

In 29 patients with follicular cytology, 27 were proceeded with surgery and postop biopsy revealed 19 patients with benign disease and 8 patients with malignant disease. In this group of patients, preoperative Doppler studies were correlated with post-operative biopsy. In other patients, Doppler studies were compared with FNAC.

\section{Statistical Analysis}

The association between the biopsy result and the qualitative variables (halo, echogenicity, margins, number of nodules, colour Doppler Study and calcification) and were assessed using likelihood chi-square test. $\mathrm{P}$ value of $<0.05$ was considered significant.

\section{RESULTS}

\section{B-Mode USG}

Based on echogenicity, sixty nine of the hundred and seventyseven nodules were hypoechoic, ten were hyperechoic, twenty were isoechoic, seventy-two were mixed and six were anechoic. Statistical analysis didn't reveal a significant statistical association between the cytological findings and the above parameters $(\mathrm{P}=0.059)$. Twenty-nine of thirty-seven malignant nodules were hypoechoic. Eighty seven of the hundred and seventy-seven nodules showed peripheral halo.

Three had suspicious cytology and only two had malignant cytology. Among the nodules without halo six were classified as suspicious, thirty-one were classified as malignant and thus the presence of halo was considered a significant evidence of benign lesion. Presence of a thick halo was a sign of malignant lesion and a thin halo was an important sign of benign lesion.

Depth, width and length measurements showed that malignant nodules were larger than indeterminate and benign nodules $(\mathrm{P}=0.001)$. Malignant nodules had an average width of $3.5 \mathrm{~cm}$ vs. $1.75 \mathrm{~cm}$ for benign nodules. 50 of the 177 nodules showed calcifications. Among 50 nodules with calcifications, 10 were coarse, fine in 37 , mixed in 3 . Twenty seven of the 37 nodules with microcalcifications had malignant cytology. Thus, the association between fine calcification and malignancy were considered statistically to be significant $(\mathrm{P}=$ 0.001). Microcalcifications were seen in twenty-four of the thirty-seven malignant nodules.

\section{Power Doppler}

Vascularisation patterns were identified with Power Doppler USG on all 177 nodules. It revealed that

- Thirteen nodules with pattern I (Absent blood flow-these patients were not subjected to pulsed Doppler as there is no flow),

- Sixty-one had pattern II (Exclusively perinodular blood flow),

- $\quad$ Sixty-six had pattern III (Perinodular blood flow equal or greater than central flow)

- Twenty-six had pattern IV (Central blood flow greater than perinodular flow)

- $\quad$ Eleven had Pattern V (Exclusively central blood flow).

In malignant nodules, pattern IV and Pattern $\mathrm{V}$ were significantly associated with malignancy. Thirty five of thirtyseven malignant nodules showed these vascular patterns.

\section{Pulsed Doppler}

In malignant nodules, mean PI is 1.54, (SD 0.033) and mean RI is 0.75 (SD 0.29). These values were statistically significant and identify malignant nodules with good accuracy.

\begin{tabular}{|c|c|c|c|c|c|c|c|c|c|c|}
\hline & \multicolumn{9}{|c|}{ Benign } & \multicolumn{5}{c|}{ Malignant } \\
\hline & n & Min. & Max. & Mean & S.D. & N & Min. & Max. & Mean & S.D. \\
\hline Age & 127 & 15 & 75 & 42.17 & 15.426 & 37 & 15 & 78 & 41.89 & 14.208 \\
\hline RI & 127 & 0.532 & 0.741 & 0.61674 & 0.043748 & 37 & 0.699 & 0.812 & 0.75319 & 0.029478 \\
\hline PI & 127 & 0.902 & 1.089 & 0.96277 & 0.031596 & 37 & 1.494 & 1.614 & 1.54873 & 0.033278 \\
\hline Stage & 140 & 1 & 3 & 2.01 & 0.802 & 37 & 3 & 5 & 4.16 & 0.602 \\
\hline \multicolumn{9}{|c|}{ Descriptive Statistics } \\
\hline
\end{tabular}

\section{DISCUSSION}

Due to the advent of technology innocent lesions are increasingly detected. As the resolution of thyroid ultrasound increases many nodules that are clinically not detected are being detected[1] resulting in diagnostic and therapeutic confusions. Although B-mode USG is the investigation of choice for thyroid lesions, it cannot reliably differentiate benign lesions from malignant lesions.[2] 
Preoperatively, we largely rely on $\mathrm{FNAC}^{[3]}$ to find the nature of lesion. Though FNAC guides us through many clinical dilemmas, it has its own disadvantages.

Increased vascularisation is well seen in tumour growth. ${ }^{[4]}$ It is now possible to identify vascular patterns inside superficial tissues with the advent of power Doppler. Thus, this tool is very useful in studying and identifying thyroid nodules that should undergo FNAC.

\section{B-Mode USG Parameters}

Most nodules were hypoechoic and mixed because we included those patients referred to our department after FNAC for screening sonography, if FNAC shows follicular cells (Indeterminate) patients were asked to proceed with pre-op Doppler and post-operative HPE report was correlated.

In our study, of the thirty seven malignant nodules identified, eight had mixed echogenicity and twenty nine had hypoechogenicity.[5]

A significant evidence of benignity was the presence of halo. Another significant indicator of malignancy was decreased halo thickness. ${ }^{[6]}$ These results are in concordance with those in other studies. USG can detect nodules in half of the population. Most of the detected nodules are less than 1.5 $\mathrm{cm}$ and are considered clinically occult nodules.

FNAC has been advocated as the prime investigation for both occult and clinically palpable thyroid nodules, generally nodules less than $1.5 \mathrm{~cm}$ are followed up with clinical examination and ultrasound.

Yet, sonographic features like microcalcifications, hypoechogenicity, irregular margins, can be exempted from followup protocol and are managed more aggressively as they may indicate malignancy. ${ }^{[7]}$

Fifty of the one seventy-seven nodules had microcalcifications and twenty-four of thirty-seven malignant nodules had microcalcification. Our data are in accordance with reports in the literature and indicates that microcalcification is a good predictor of malignancy and is present in close to 65 percent of malignant nodules. [8]

\section{Power Doppler Indices}

Power Doppler helped to identify low velocity blood flow in vessels that previously could not be visualised. We adopted our own classification, based on vascular patterns by modifying the one proposed by "Lagalla et al".[9] Our classification includes the followings 5 vascular patterns:

- Absence of blood flow- Pattern I.

- Exclusively perinodular blood flow- Pattern II.

- Perinodular blood flow pattern is equal to central blood flow - Pattern III.

- $\quad$ Blood flow- Central blood flow > perinodular blood flow pattern IV.

- $\quad$ Exclusively central blood flow - pattern V.

Nodules with vascular pattern III have a peripheral ring on USG colour Doppler.

Thirteen of the one seventy-seven nodules in my study had no blood flow and no malignant nodule is listed in this group. These results are similar to number of published reports, where absence of blood flow signal is seen only in benign lesions.[10]

Though both perinodular and central blood flow pattern is seen in both benign and malignant nodules, central predominant flow is seen in malignant groups and perinodular predominant patterns are seen in benign disease.[11]

As the intranodular blood flow becomes more dominant the risk of malignancy increases,[12] e.g. a small number of nodules with pattern III blood flow (two of sixty six nodules) were malignant whereas twenty four of twenty six nodules with pattern IV blood flow and all nodules with pattern $V$ blood flow were malignant. Holden identified carcinomas as having more concentrated intranodular blood flow.[13]

Cerbone et al[14] performed various studies and analysed patterns of flow and increase in vascularity in malignant lesions and found that pattern of flow (central predominance) is more associated with malignancy, than increase in vascularity.

On comparing observed vascular patterns with our cytological findings, we found that most benign nodules had vascular patterns II or III and accounted for 127. Though Pattern I and Pattern II (marked) goes more in favour of benign nodules, pattern III is found in both benign and malignant diseases. 35 of the 37 malignant nodules are associated with malignancy.[15]

Doppler detection of nature of thyroid swelling depends on many technical aspects, like wall pulse repetition frequency, filter signal amplification, Doppler sensitivity, intervening tissue attenuation and depth of region of interest. ${ }^{[4]}$ Even breathing and swallowing can create artefacts minimising the utility of application. In this study, standard guidelines have been used to minimise these disadvantages.[16]

Analysing the vascular patterns is rather subjective than objective, though guidelines have been followed in categorising patterns, still it is prone for error. This can be overcome by integrating the technology and software in to modern USG such that it objectively interprets patterns.[17]

\section{CONCLUSION}

USG evaluation of thyroid nodules by using power Doppler can effectively differentiate nodules with high risk for malignancy from benign nodules. Power Doppler and RI have a high sensitivity and specificity in detecting malignancy. Patients showing follicular cells in FNAC can reliably be differentiated into benign and malignant groups using Doppler sonogram, which can bridge the limitation of FNAC which cannot identify malignant follicular neoplasm.

\section{REFERENCES}

[1] Solbiati L, Livraghi T, Ballarati E, et al. Ultrasound superficial structure: high frequencies, Doppler interventional procedure. New York: Churchill Livingstone 1995.

[2] Blum M, Yee J, Oppenheimer JH. Advances in thyroid imaging: thyroid sonography when and how should it be used? Thyroid Today 1997;20:1-13.

[3] Sabel MS, Haque D, Velasco JM, et al. Use of ultrasoundguided fine needle aspiration biopsy in the management of thyroid disease. Am Surg 1998:64(8):738-41.

[4] Tramalloni J, Leger A, Correas JM, et al. Imagerie du nodule thyroidien. J Radiol 1999;80(3):271-7. 
[5] Brander AE, Viikinkoski VP, Nickels JI, et al. Importance of thyroid abnormalities detected at US screening: a 5year follow up. Radiology 2000;215(3):801-6.

[6] Shimamoto K, Satake H, Sawaki A, et al. Preoperative staging of thyroid papillary carcinoma with ultrasonography. Eur J Radiol 1998;29(1):4-10.

[7] Solboati L, Cioffi V, Ballarati E. Ultrasonography of the neck. Radiol Clin Noirth Am 1992;30(5):941-54.

[8] Ross DS. Evaluation of the thyroid nodule. J Nucl Med 1991;32:2181-92.

[9] Lagalla R, Caruso G, Novara V, et al. Analisi flussimetrica nella patologia titoidea: ipotesi di integrazione con to studio qualitative con-color Doppler. Radiol Med 1993;85:606-10.

[10] Rsener B. Fundamentals of biostatistics. $2^{\text {nd }}$ edn. Boston MA: PSW publishers 1986.

[11] Burns P. Interpreting and analyzing the Doppler examination. In: Taylor KJW, Burns P, Wells PNT. 2nd edn. Clinical applications of Doppler ultrasound. New York: Raven Press 1995:55-98.
[12] Rago T, Vitti P, Chiovato L, et al. Role of conventional ultrasonography and color flow-Doppler sonography in predicting malignant in cold thyroid nodules. Eur J Endocronic 1998;138(1):41-6.

[13] Holden A. The role of colour and duplex Doppler ultrasound in the assessment of thyroid nodules. Australian Radiol 1995;39(4):343-9.

[14] Cerbone G, Spiezia S, Colao A, et al. Power Doppler improves the diagnostic accuracy of color Doppler ultrasonography in cold thyroid nodules: follow-up results. Horm Res 1999;52(1):19-24.

[15] Takashima S, Fukuda H, Nomma N, et al. Thyroid nodules: re-evaluation with ultrasound. Clin ultrasound 1995;23(3):179-84.

[16] Ahuja AT. The thyroid and parathyroid. In: Ahuja A, Evans R (eds). Practical head and neck ultrasound. London: UK Greenwich Medical Media 2000:37-59.

[17] Gritzmann N, Koischwitz D, Rettenbacher T. Sonography of the thyroid and parathyroid glands. Radioal Clin North Am 2000;38(5):1131-45. 